\title{
Critical role of nitric oxide in impeding COVID-19 transmission and prevention: a promising possibility
}

\author{
Rajalakshmi Rajendran ${ }^{1}$ - Anjana Chathambath ${ }^{1} \cdot$ Abdullah G. Al-Sehemi $^{2,3} \cdot$ Mehboobali Pannipara $^{2,3}$. \\ Mazhuvancherry Kesavan Unnikrishnan ${ }^{4} \cdot$ Lotfi Aleya $^{5} \cdot$ Roshni Pushpa Raghavan $^{1} \cdot$ Bijo Mathew $^{6}$ (i)
}

Received: 8 August 2021 / Accepted: 6 February 2022 / Published online: 8 March 2022

(c) The Author(s), under exclusive licence to Springer-Verlag GmbH Germany, part of Springer Nature 2022

\begin{abstract}
COVID-19 is a serious respiratory infection caused by a beta-coronavirus that is closely linked to SARS. Hypoxemia is a symptom of infection, which is accompanied by acute respiratory distress syndrome (ARDS). Augmenting supplementary oxygen may not always improve oxygen saturation; reversing hypoxemia in COVID-19 necessitates sophisticated means to promote oxygen transfer from alveoli to blood. Inhaled nitric oxide (iNO) has been shown to inhibit the multiplication of the respiratory coronavirus, a property that distinguishes it from other vasodilators. These findings imply that NO may have a crucial role in the therapy of COVID-19, indicating research into optimal methods to restore pulmonary physiology. According to clinical and experimental data, $\mathrm{NO}$ is a selective vasodilator proven to restore oxygenation by helping to normalize shunts and ventilation/perfusion mismatches. This study examines the role of NO in COVID-19 in terms of its specific physiological and biochemical properties, as well as the possibility of using inhaled NO as a standard therapy. We have also discussed how NO could be used to prevent and cure COVID-19, in addition to the limitations of NO.
\end{abstract}

Keywords SARS CoV-2 $\cdot$ COVID-19 $\cdot$ Nitric oxide $\cdot$ Vasodilation $\cdot$ Mechanical ventilation

Responsible Editor: Philippe Garrigues.

Roshni Pushpa Raghavan

roshnipr@aims.amrita.edu

1 Department of Pharmacy Practice, Amrita School of Pharmacy, Amrita Vishwa Vidyapeetham, Kochi 682041, Kerala, India

2 Research Center for Advanced Materials Science, King Khalid University, Abha 61413, Saudi Arabia

3 Department of Chemistry, King Khalid University, Abha 61413, Saudi Arabia

4 NGSM Institute of Pharmaceutical Sciences, Nitte Deemed To Be University, Manglore 575018, India

5 Laboratoire Chrono-Environment, Universite de Bourgogne Franche-Comte, CNRS6249 Besancon, France

6 Department of Pharmaceutical Chemistry, Amrita School of Pharmacy, AIMS Health Sciences Campus, Amrita Vishwa Vidyapeetham, Kochi 682 041, India

\section{Introduction}

Coronaviruses (CoVs) are RNA viruses that predominantly infect birds and mammals. These viruses typically have a genome of $\sim 30$ kilobase $(\mathrm{kb})$, named after the protruding coronary spikes on the virus's surface (Fehr and Perlman 2015). According to the World Health Organization, $356,955,803$ confirmed cases of COVID-19 have been reported, with 5,610,291 deaths (WHO 2022). Depending on the nation and age group, the death rate has changed significantly. Although some individuals are asymptomatic, COVID-19 symptoms include fever, dry cough and myalgia. COVID-19 exhibits histological similarities with SARS and MERS in worsening lung injury and sepsis, which are the primary causes of mortality (Takahashi et al. 2020; Lu et al. 2020; Amoretti et al. 2002). Based on these characteristics, SARS-CoV-2 is a member of the SARS-CoV genus and infects cells by a specific method that involves the S-protein attaching to the membrane receptor angiotensin converting enzyme 2 (ACE-2). Despite having identical genomic structures, SARS-CoV-2 has a greater infectivity than SARS-CoV-1(Kumar et al. 2021a, b, c; Kumar et al. 2021a, 2021b). 
There is currently no particular pharmacological therapy or vaccination available to treat COVID-19. Many research organisations across the globe have evaluated prospective antimalarial medications including hydroxychloroquine and azithromycin, antifilarial drug ivermectin and antiviral treatments for their probable action against the COVID-19 initially. Hydroxychloroquine and ivermectin have been shown to inhibit viral import by acidifying cells. Some other drugs such as favipiravir, remdesivir, umifenovir, teicoplanin, doxycycline and dexamethasone when used in conjunction with immunotherapy were also found effective in combating the pandemic (Siddiqui et al. 2021). Moreover, in preclinical and clinical studies, various natural plant substances are also studied. (+)-Calanolide A and SP-303 are two plantbased antiviral agents in clinical development for COVID19. Calanolide $A$ is a $C 22$ coumarin that is primarily used to treat HIV infection and is derived from the plant Calophyllum langigerum, which is mostly found in Malaysia and Indonesia (Creagh et al. 2001; Currens et al. 1996; Ubillas et al. 1994). SP-303, on the other hand, is made up of oligomeric proanthocyanidins with a molecular weight of 2100 Daltons and is derived from the latex of Croton lechleri, a Latin American plant (Wyde et al. 1993). Despite the fact that the process of drug development from natural products is time-consuming, their efficacy has been shown to be effective over an extended period of time. Surprisingly, recent research has identified mesenchymal stem cells (MSCs) as a possible treatment strategy for SARS-CoV-2 (Alzahrani et al. 2020). It is believed that MSCs inhibit viral infections via the release of particular cytokines; these characteristics are inherently present when the MSCs are in their niche prior to being separated from the parent tissue (Nile et al. 2020). Therefore, MSCs and their exosomes (MSC-Exo) are likely to survive even when transplanted into patients who are infected with SARS-CoV-2 (NCT04276987). The reported clinical studies are being examined in order to provide information to researchers investigating stem cell-based therapies for SARS-CoV-2 infection because it is ambiguous. An investigation into the inhibitory ability of a bioactive sponge metabolite, ilimaquinone, targeting nine putative SARS-CoV-2-specific proteins that have been identified as attractive therapeutic targets is being carried out in the laboratory. In the search for effective therapeutic development against COVID-19, the findings of this study promise to provide the groundwork for future validation of the inhibitory ability of the ilimaquinone in vitro and in vivo, as well as its use as an efficient inhibitor of SARS-CoV-2 papain like protease (Surti et al. 2020).

Recent research suggests that ventilator treatment is ineffective and may possibly increase morbidity and mortality (Richardson et al. 2020). A heated controversy has erupted over the use of inhaled nitric oxide (iNO) in the treatment of severe hypoxia caused by COVID-19. With the little clinical evidence to support it, the surviving sepsis campaign advised the use of iNO as a rescue therapy in such patients with persistent hypoxia. Also emphasising that this treatment should be tapered down if there is no improvement after $24 \mathrm{~h}$ (Abou-Arab et al. 2020).

Nitric oxide is vital to the cardiovascular, respiratory and immunological systems (NO). Where NO is generated and concentrated determines its function. Abnormal NO levels are usually associated to the development and progression of illnesses, such as viral infection (Alamdari 2020). The role of NO, possible mechanism and therapeutic use in COVID19 have yet to be thoroughly investigated. NO was studied in COVID-19 from the standpoints of its general characteristics: six recognized pathways in the lungs, potential functions in COVID-19 aetiology and therapeutic application in COVID-19 prevention and therapy.

\section{Bioavailability studies of NO in COVID-19}

When measured as nitrate and nitrite (NO metabolites) in severe COVID-19 patients, the generation of NOx was much higher compared to healthy people (controls) (Kleinbongard 2003). Activation of macrophages is predicted during an inflammatory immunological response. Inflammation can cause the inducible synthase of nitric oxide (iNOS) in macrophages to activate by $2-3$ times, producing a high amount of $\mathrm{NO}$ and causing a local and systemic increase in nitrate and nitrite (Fraser 2020). However, thrombotic factor profiling with immunoassays and studies with human pulmonary microvascular endothelial cells indicated that patients who sustained significant COVID-19 incurred excessive and irreversible endothelium damage, according to an original Canadian clinical research (Becker 2020). Moreover, autopsy and surgical tissue specimens showed diffuse lypothelitis and apoptotic body diseases (Ozdemir and Yazici 2020). Moreover, COVID-19-related complications were associated with substantial decrease in endothelial NO (Amraei and Rahimi 2020), demonstrating a closely linked pulmonary injury and a NO/ROS imbalance (Varga 2020). iNOS and eNOS estimations have suggested involvement of NO pathways during infection ( $\mathrm{Li}$ et al. 2020). The following four pathways are potentially involved in SARS-CoV-2 infection (see Fig. 1).

Although the major location of COVID-19 infection is bronchial ciliated epithelium and pulmonary type II cells, electron imaging has detected leftover virus particles in endothelial cells. Infections in endothelial cells enhance apoptosis and decrease endothelial NO production (Banu et al. 2020). Furthermore, the progression of viral infection also reduces NO generation. The SARS-CoV-2 glycoprotein-S protein infects host cells by binding to angiotensin-converting enzyme 2 (ACE2) (Gopal and Varma 2020). ACE converts angiotensin-I to 


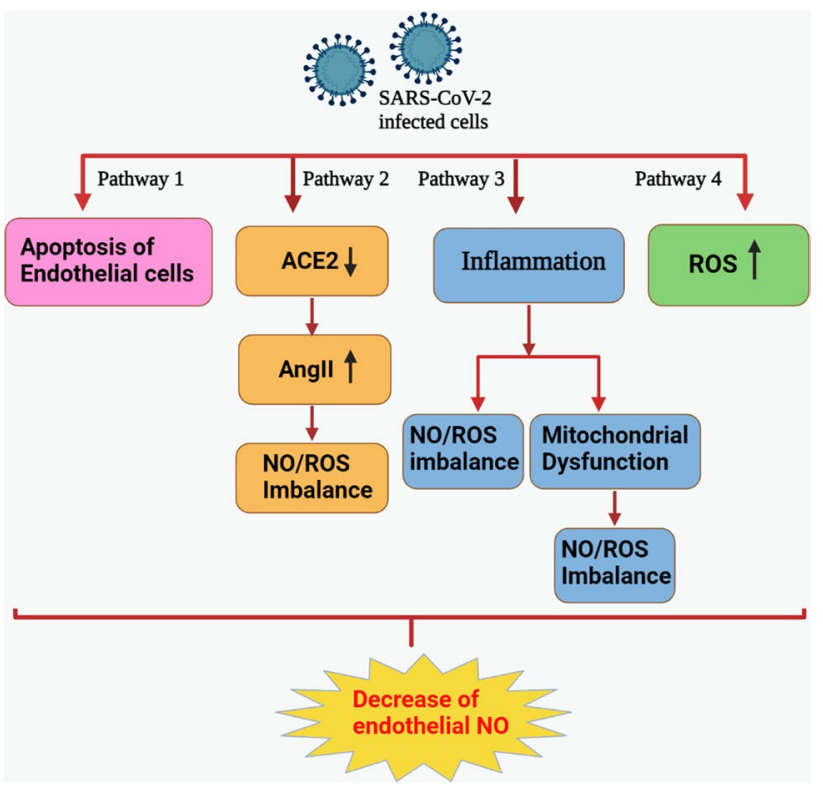

Fig. 1 Four possible mechanisms in COVID-19 aetiology regulate NO levels and bioavailability

angiotensin-II (AngII) and promotes NO production by endothelial cells (Al-Sehemi et al. 2020). The removal of ACE2 and its upstream product AngII are assuaged by downregulation of ACE2. ACE suppresses NO production while promoting the production of ROS and inflammation. AngII also stimulates macrophages to produce inflammatory cytokines and reactive oxygen species (ROS), resulting in increased inflammatory responses and an imbalance of NO/ROS (England et al. 2021; Clark 2007). Inflammation is the immune system's natural reaction to trauma and threats. Infections with viruses cause a substantial increase in inflammatory cytokines in the peripheral circulation, setting off a strong cytokine storm (Channappanavar 2017; Song et al. 2020). When intense inflammation lasts for an extended period, inflammation also damages many tissues and organs. Furthermore, inappropriately intense inflammation contributes to an imbalance of reactive oxygen species which leads to oxidative stress (Shenoy 2020). Inflammatory cytokines and chemokines are found in the serum of patients with severe COVID-19, which promote excessive ROS production in the mitochondria, ultimately leading to oxidative damage and cell death (Nambiar et al. 2018; Guzik et al. 2003). ROS also alters vascular tone by raising intracellular calcium concentration and decreasing NO bioavailability (Uehara et al. 2015).

The impact and bioavailability of NO in COVID-19 patients are intimately connected to the development of disease (Gibaldi 1993). The general biochemistry of NO will be discussed below for a better understanding of its function in COVID-19.

\section{Role of cytokines in SARS CoV-2 infection}

Immune cells and molecules are mobilised in a rapid reaction to viral, bacterial or other microorganism infection, drawing on metabolic resources (O'Neill 2015; Wu et al. 2016; Bambouskova et al. 2018). It is necessary to reprogram the host metabolism in order to create efficient antiviral defensive responses in response to metabolic dysfunctions induced by viral infection. The molecular processes underpinning the innate immune response to viral infection are revealed by studies on virus-cytokine interactions (Agalioti et al. 2000; Cheng et al. 2014; Sanchez and Lagunoff 2015).

Cytokines are polypeptide signalling molecules that regulate several biological processes through cell surface receptors (Bartee and McFadden 2013). Among the most important cytokines are those that are involved in adaptive immunity (e.g. interferon (IFN)-I, -II and -III; proinflammatory cytokines and interleukins (ILs) (e.g. interferon (IFN)-1, -II, and -III; IL-1, IL-6, and IL-17 and TNF- $\alpha$ ) and anti-inflammatory cytokines (such as IL-10)). To respond defensively to stress-inducing internal events such as tumours and infections, host cells generate cytokines, which play a critical function in the regulation of cell metabolism (Turner et al. 2014; Vabret et al. 2020). Cytokines are proteins that play a significant role in the regulation of cell metabolism. Blanco-Mello et al. (2020) reported a different and inappropriate inflammatory response associated with SARS-CoV-2 infection in the context of COVID-19 illness in the literature. According to these researchers, people with comorbidities are more likely to have an "inappropriate and weak immune response" than those without. As a result, viral replication may be favoured, and problems associated with severe instances of the illness may be exacerbated.

COVID-19 has been the subject of a large number of studies, and abnormal levels of many cytokines and chemokines have been noted in the patients: IL-1, IL-2, IL-4, IL-6, IL-7, IL-10, IL-12, IL-13, IL-17, G-CSF, GMCSF, IP-10, IFN- $\gamma$, MCP-1, MIP 1- $\alpha$ (Huang et al. 2020; Liu et al. 2020; Wang et al. 2020c; Chen et al. 2020a, b). An increase in inflammatory cytokines and a decrease in antiviral defences associated with the innate immune system may be the most important factor in SARS-CoV-2 infection.

Multiple clinical indications, such as IFN- $\gamma$ production, which results in symptoms such as headaches, chills, dizziness and fever, are strongly connected with the release of several cytokines. In addition to causing flulike symptoms, such as fever, exhaustion and malaise, TNF- $\alpha$ also causes lung damage, vascular leakage, heart failure and the production of acute-phase proteins 
Shimabukuro-Vornhagen et al. (2018), along with other complications. Vascular leak syndrome is caused by the production of IL-6, which activates the coagulation and complement pathways, resulting in the most conspicuous manifestations of cytokine release syndrome (Hunter and Jones 2015; Tanaka et al. 2016). Notably, IL-6 promotes coronary artery disease and myocardial dysfunction, resulting in cardiomyopathies (Pathan et al. 2004). Furthermore, significant cytokine release syndrome may arise as a consequence of the stimulation of endothelial cells, and endothelial dysfunction can result in hypotension and poor blood coagulation. Taking into account of these findings, it appears that the virally induced immunopathological responses are crucial to the development of fatal pneumonia. About 150 chemical mediators and inflammatory cytokines are secreted by NK cells, macrophages and T cells (Teijaro et al. 2014). Apoptosis of endothelial and epithelial cells of the lung occurs during viral invasions, causing hypoxia, alveolar oedema and vascular leakage. Lengthy exposure to pro-inflammatory chemokines and chemokine receptor antagonists leads to lung scarring and mortality (Reghunathan et al. 2005).

\section{Nitric oxide, oxidative stress and inflammation}

Endothelial dysfunction is termed when vasodilator substances, like NO, become less bioavailable, while vasoconstrictor substances become more abundant.

When NO bioavailability is reduced, it might be due to eNOS deficiency, a lack of cofactors essential for eNOS formation on one hand, as well as excessive NO breakdown or inactivation from reactive oxygen species (ROS) on the other (Cai and Harrison 2000). Increasing the formation of reactive oxygen species (ROS) such as superoxide anion $\left(\mathrm{O}^{2-}\right)$, hydrogen peroxide $\left(\mathrm{H}_{2} \mathrm{O}_{2}\right)$, hydroxyl radical $(\mathrm{HO} \bullet$ ), hypochlorous acid $(\mathrm{HOCl})$ and lipid superoxide radical in cardiovascular disorders is the primary cause of the reduction in NO bioavailability (Maadamanchi et al. 2005). ROS generation is regulated by an efficient system of antioxidants, molecules capable of neutralising ROS and thereby reducing oxidative stress, under physiological circumstances. To convert ROS to oxygen and water, endogenous enzyme antioxidants such as SOD, glutathione peroxide and catalase are required. ROS may be present in excess compared to the antioxidant capability in pathogenic situations. A shift in the equilibrium in favour of oxidation, or 'oxidative stress', may negatively affect cell and tissue function. Endothelial cells (ECs) have a multitude of strategies for reducing oxidative stress in the immediate environment. The endothelium generates SOD in response to shear stress, which neutralises
ROS (Gimbrone and García-Cardeña 2016). Glutathione peroxidase, which may reduce oxidative stress, can also be expressed by endothelial cells [15]. Similarly, haem-oxygenase (Nagy et al. 2010; Quan et al. 2001) offers another way for the endothelium cell to withstand local oxidative stress. Proinflammatory cytokines, on the other hand, might activate NADPH-oxidase in endothelial cells, increasing local oxidative stress (Pennathur and Heinecke 2007; Teuwen et al. 2020).

A high concentration of Ang II can cause oxidative stress, as well as a low concentration of Ang 1-7 (Fig. 2). Some of these ROS can oxidise the cysteine residues in the peptidase domain of the receptors ACE2 and RBD of the proteins SARS-CoV and SARS-CoV-2, keeping them in oxidised forms (disulphide) instead of in their reduced form (thiol) (Nordberg and Arnér 2001). The oxidative stress pathway may enhance the affinity of SARS-CoV and SARSCoV-2 S for ACE2 receptors, hence increasing the severity of COVID-19 infection (Hati and Bhattacharyya 2020). It was recently shown that the SARS-CoV-2 virus has longterm effects on oxidative stress and the endothelium of the vascular endothelium (Chang et al. 2020). This led to the hypothesis that SARS-CoV-2, by producing mitochondrial dysfunction and oxidative stress, might set off a feedback loop that promotes a persistent state of inflammation and endothelial dysfunction long after the virus particles have been cleared from the body. Consequently, according to this suggested mechanism, SARS-CoV-2 first activates NADPH-oxidase, which results in the production of superoxide $\left(\mathrm{O}^{2-}\right)$, a reactive oxygen species (ROS) that is implicated in processes that degrade the electron transport chain (ETC) (Nguyen Dinh Cat et al. 2013; Li et al. 2013). Due to this mitochondrial dysfunction, there is an increase in oxidative stress and inflammation, which results in a feedback loop that keeps NADPH-oxidase activated, as well as inflammatory cytokine production and the loss of EC's identity. In light of these putative long-term implications of SARS-CoV-2 infection on blood arteries, treating chronic oxidative stress and inflammation in the EC may be critical in averting future difficulties among the millions of people who have been diagnosed with COVID-19 (Petersen et al. 2020).

\section{Biochemical characteristics of NO}

NO is a highly reactive molecule (Star 1993) that interacts with a wide range of reagents and regulates a number of signalling pathways. NO binds to metal centres, DNA and lipid-free radicals directly (Tripathi 2007). When nitric oxide (NO) reacts with oxides $\left(\mathrm{O}_{2}\right)$ or free radicals $\left(\mathrm{O}_{2}{ }^{-}\right)$, reactive species are formed that damage target molecules (Susswein et al. 2004). 


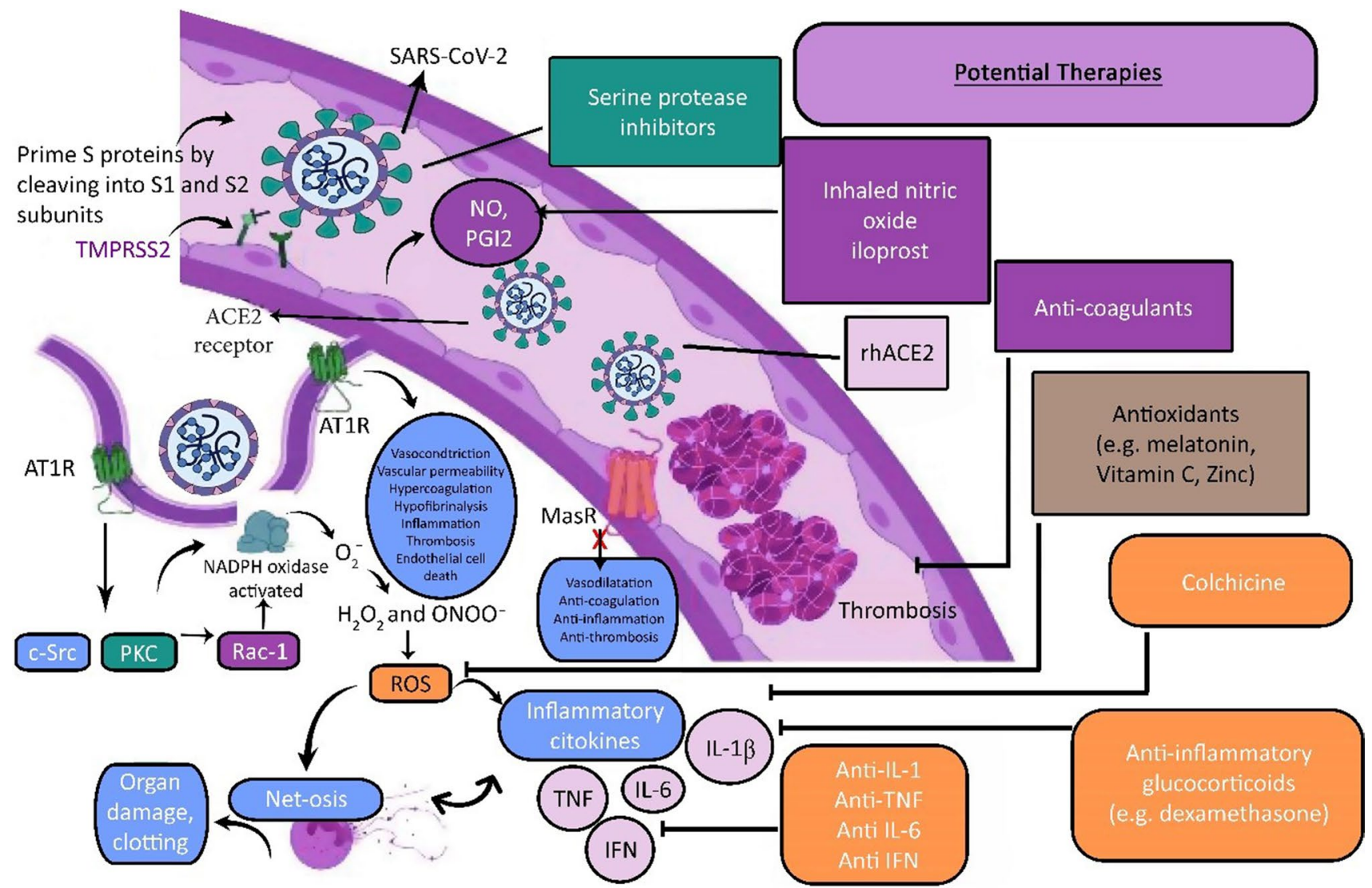

Fig. 2 This figure depicts the mechanism of endothelial dysfunction and oxidative stress, with possible therapeutic targets in COVID-19. Initiation of COVID-19 infection is by the binding of viral proteins to the TMPRSS2 and ACE2. This is followed by the viral uptake into the endothelial cells. This enhances the binding of Ang-II to AT-1R and activates NADPH-oxidase whereby resulting in increased production of ROS. Various signalling pathways get activated by ROS and subsequently results in increased production of various interleukins. Thus, the availability of endogenous $\mathrm{NO}$ and prostaglandin and its analogues is decreased for its action, leading to endothelial dam-

Inducible NO synthase responsible for the synthesis of nitric oxide is found predominantly in macrophages and monocytes (Alvarez et al. 2020; Lee and Butt 2020). Depending on its source and concentration, NO has a dual function in various pathophysiological processes, including blood circulation and inflammatory response (Michel 1998) (Fig. 2).

\section{The critical role of $\mathrm{NO}$ in the respiratory system}

NO is an effective vasodilator and immune regulator (Friebe et al. 2020; Ricciardolo et al. 2020; Bohlen 2015; Teixeira et al. 2020). NO works by dilating bronchial/airway to promote oxygen uptake and also acts as a vascular anticoagulant age and destruction. Moreover, increased production of proinflammatory markers and prothrombotic factors consequently obstructs the blood vessels including the heart and lungs and results in organ damage. Therapeutic targets that could be beneficial in the mechanism are also mentioned in the figure. TMPRSS 2 transmembrane protease, serine 2; ACE2 angiotensin-converting enzyme 2; AT1R angiotensin type 1 receptor; ROS reactive oxygen species; c-Src protooncogene tyrosine-protein kinase Src; PKC protein kinase C; IL interleukin; TNF tissue necrosis factor; NO nitric oxide; PGI2 prostaglandin I2 (also known as prostacyclin)

and antiplatelet agent. NO functions as an anti-inflammatory agent, by inhibiting early non-specific immunity, by modifying vascular inflammatory events and immune cell proliferation (Goeijenbier 2012). NO also has an antiviral action by inhibiting SARS-CoV-1/SARS-CoV-2 replication (Martel et al. 2020a). NO also operates in COVID-19 by four additional mechanisms, namely regulating blood flow, initiating anti-inflammatory responses, promoting anti-coagulation effects and exerting antiviral properties ( $\mathrm{Ng} 2005)$.

\section{Effects on vasodilation}

The plausible mechanism of action of NO in vascular smooth muscle is illustrated in Figs. 3 and 4.

Furthermore, NO is active in the S-nitrosothiol (RSNO) metabolic pathways. In an aerobic environment, RSNO has 


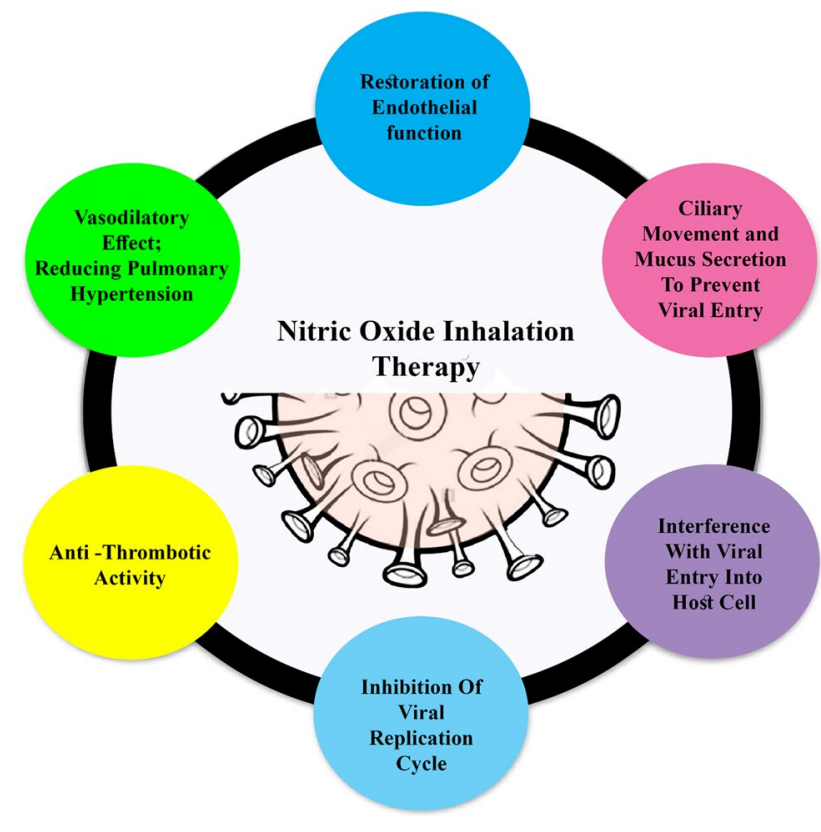

Fig. 3 Protective role of inhaled nitric oxide in mitigating COVID-19 infection

a half-life of $40 \mathrm{~min}$ (anaerobic NO has a half-life of 1-5 s, aerobic $3 \mathrm{~s}$ ). It exerts a potent bronchodilator action that is independent of the cGMP pathway, lowering airway stress and increasing oxygen uptake (Akter et al. 2016).

Vascular impairment and reduced endothelial NO production or bioavailability are often associated with hypertension, diabetes and cardiovascular disorders (Rimmelzwaan et al. 2001). The abovementioned disorders have been the most common comorbidities that urge hospitalization in COVID-19 patients, compared to other chronic conditions. A meta-analysis showed that the average incidence of asthma, coronary and cerebrovascular disorders and diabetes was $17.1 \%, 16.4 \%$ and $9.7 \%$, respectively, in six Chinese trials involving 1527 COVID-19 patients (Karupiah and Harris 1995), implying that NO could play an important role.

\section{Effects on coagulation}

Anticoagulants such as heparin, prostaglandin and NO are produced by endothelial cells (Drucker 2020). L-arginine catalysed by calmodulin-dependent NOS produces NO under normoxia, protecting arteries from platelets and circulating cells, thus supporting physiological vascular tissue homeostasis. Endothelial cell dysfunction causes pathological alterations such as reduced or interrupted NO release, depending on the severity of damaged NO causes chronic vasoconstriction and a hypercoagulable state in blood by increasing the amounts of free $\mathrm{Ca}^{2+}$ in vascular smooth muscle cells. Platelets secrete a plethora of pro-inflammatory mediators that include vascular growth factors. Platelets migrate to the damaged area to form platelet clots and form a complex with plasma factor VIIa, which then interacts with extravascular tissue to activate thrombin. As thrombin converts soluble fibrinogen to insoluble fibrin, the platelet plug becomes entangled with blood cells, creating a thrombus. Thrombus formation reduces endothelial NO production due to endothelial tissue damage.

Individuals with SARS and MERS who are critically ill are manifested with abnormal coagulation and a poor prognosis (Wu and McGoogan 2020; Tavazzi et al. 2020a). A recent research report says that a key pathogenic event in
Fig. 4 The role of nitric oxide in the physiology of vasodilation of vascular smooth muscle

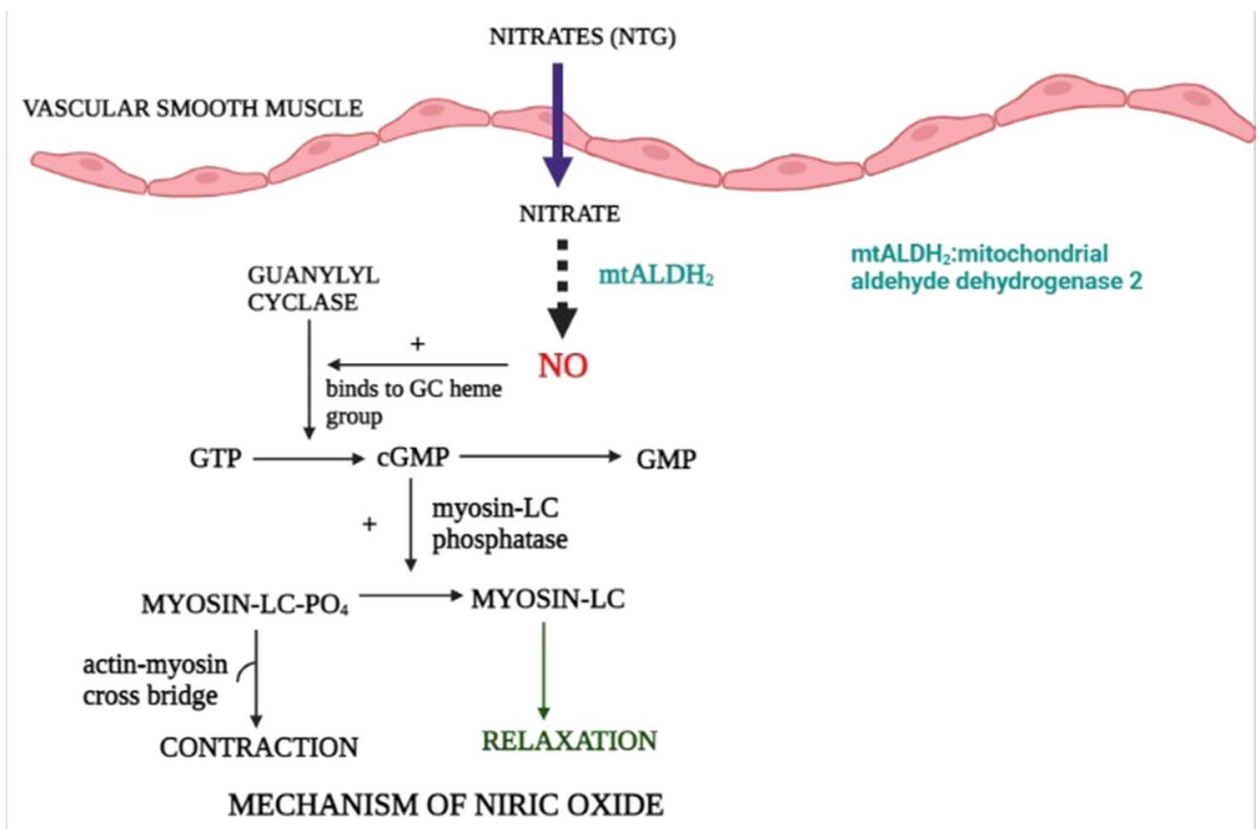


COVID-19 is a hypercoagulable state. A major reason for increase in COVID-19 mortality is distal thrombotic problems (Ferrari et al. 2020). In COVID-19 individuals, early coagulation issues included a significant rise in D-dimer and fibrin breakdown products, which leads to disseminated intravascular coagulation (DIC) in severe instances (Mahjoub et al., 2020). Patients diagnosed with COVID-19 had a substantial rise in D-dimer during hospitalisation, according to a clinical report from Jinyintan Hospital in Wuhan (Klinger 2002; Monsalve-Naharro et al. 2017; Haddad et al. 2000). In these infected individuals, both the activated partial thromboplastin time (APTT) and the prothrombin time (PT) were considerably increased (Sahni et al. 2017; Rossaint et al. 2014; Gebistorf et al. 2016), indicating a risk of thrombosis.

\section{Effects on inflammation}

Inflammation is a critical defence mechanism for inactivating pathogens, removing irritants and paving the way for tissue healing (Busè et al. 2018). Excessive inflammation, on the other hand, causes harm. NO has been proven to either promote or inhibit practically every step of inflammation (Everett et al. 2016). During infections, immune cells employ germline-encoded pattern recognition receptors (PRRs) to recognize infiltrating viruses. PRRs detect exogenous pathogen-associated molecular patterns (PAMPs) and activate the NF- $\mathrm{KB}$ and MAPK pathways. The transcription of iNOS is induced by NF- $\kappa \mathrm{B}$ and activator protein (AP-1) resulting in a rise in NO concentration. NO-induced metabolic events generate cytotoxicity, preventing further spread of infections. The bactericidal impact of NO generated by iNOS is primarily focused on bacteria in the cytoplasm since immune cells are the primary effector cells of iNOS production. NO can also destroy extracellular infections through diffusion because of its membrane permeability (Thachil 2020).

Furthermore, NO regulates vascular inflammation by reducing vascular dysfunction and minimizing consequences of tissue oedema and respiratory failure induced by vascular leakage. Inflammation-induced vascular damage is reduced by NO (Toolsie et al. 2019). Furthermore, NO suppresses immune cell growth during inflammatory responses. NO suppresses the production of cytokines and other immune cells, including critical inflammatory cytokines (Buckley et al. 2021). As a result, excessive inflammatory effects are reduced, and NO prevents unrestrained physical injury (Mannick 2006).

\section{Antiviral activity}

NO has non-specific antiviral effects in several viral illnesses, including AIDS-HIV, coronavirus virus, rotavirus and adenovirus (Xu et al. 2006; Boutin et al. 2021). After inhibiting iNOS with NG-monomethyl-L-arginine acetate (L-NMMA) or nitro-L-arginine methyl ester (L-NAME), the viral load rose considerably (Croen 1993). SARS-CoV-1 was also effectively reduced by exogenous NO donors. The mechanism is described below.

\section{Effect on SARS-CoV-2 viral lifecycle}

A Swedish team investigated the effect of NO donors on SARS-CoV-1 infection in VeroE6 cells in 2004 (Akerström et al. 2005). According to the findings, SNAP decreased SARS-CoV-1 replication at both the RNA and cellular levels in a dose-dependent manner. In addition, researchers observed that iNOS expression was associated with $82 \%$ less offspring viruses.

The non-structural proteins nsp1-nsp16 were involved in SARS-CoV-1 replication. The latter contains two cysteine proteases, which will be explored further below (Keyaerts et al. 2004; Chen et al. 2020a, b). 'pp1ab' replicase polyproteins are cleaved by cysteine protease with varying degrees of effectiveness. Two novel high-molecular-weight peptides were discovered after treatment with SNAP. NO inhibits the enzyme influencing the synthesis of non-structural proteins and stopping viral RNA replication (Connors and Levy 2020; Long et al. 2020).

It was observed that SNAP administration significantly reduced the quantity of palmitoylated $S$ protein. The results showed that the pseudo-typed virus's entry efficiency was substantially decreased after SNAP treatment, and the viral infection rate dropped by about $70 \%$ (Kuprash and Nedospasov 2016). During viral infection, $\mathrm{O}^{2-}$ is produced, which quickly combines with NO to generate peroxynitrite (ONOO -) (Korhonen et al. 2005), a viral inhibitor.

Peroxynitrite, which is generated as a result of the interaction between free NO in solution and superoxide anion radical $\left(\mathrm{O}^{2-}\right)$, has been shown to increase viral RNA mutation rate and lower the infectivity of viral particles (Akaberi et al. 2020; Klingström et al. 2006; Akaike et al. 2000). In the presence of free $\mathrm{NO}$ and nitrogen dioxide $\left(\mathrm{NO}_{2}\right)$, dinitrogen trioxide $\left(\mathrm{N}_{2} \mathrm{O}_{3}\right)$ is produced, and this ion may donate the nitrosonium ion $\left(\mathrm{NO}^{+}\right)$and mediate the nitrosation of viral proteins and cellular host components, both of which are important for the virus life cycle (Bi and Reiss 1995; Colasanti et al. 1999). SNAP's ability to prevent CPE at high doses while not totally inhibiting viral reproduction may be explained by one of these methods. Similarly to the Coxsackievirus 3C cysteine protease, SARS-CoV-2 3CL cysteine protease may be a potential target for S-nitrosation, with suppression of the protease activity and resultant decrease in viral replication (Saura et al. 1999). Scientists proved in a research that NO may limit the replication of SARS-CoV-2 in the Vero E6 cell line, and they identified the 
SARS-CoV-2 primary protease as a target for the antioxidant. In order to combat the ongoing COVID-19 pandemic, there is an urgent need for effective antivirals against SARS$\mathrm{CoV}-2$ to be developed.

\section{NO in COVID-19: a possible mechanism}

The infection processes of SARS-CoV-2 and SARS-CoV-1 are identical since both rely on viral $S$ protein-mediated membrane fusion with the host cell receptor ACE2 to allow viral genetic information insertion (Ramachandran et al. 2018). Cryogenic electron microscopy was used to map the SARS-CoV-2 S protein, a trimer with numerous glycosylation modifications. It has a protein sequence that is extremely similar to the SARS-CoV-1 S protein (Kvietys and Granger 2012). Although the $S 2$ region (mediated membrane fusion) is almost identical, the $\mathrm{S}$ protein receptor region (RBD) differs in amino acid residues. This distinction has been shown to enhance entry mechanism of CoV-2 into SARS-infected cells (Guo and Thomas 2017; Hermann et al. 1997).

As a result, NO may inhibit SARS-CoV-2 in the same way as it inhibits SARS-CoV-1. NO also inhibits viral replication by lowering $\mathrm{S}$ protein palmitoylation and blocking one or two cysteine proteases encoded by SARS-CoV-2 ORF1a (Saura et al. 1999; Akerström et al. 2005). However, the mechanism of NO in SARS-CoV-2 is unclear. Researchers have recommended $\mathrm{NO}$ in conjunction with clinically authorised antiviral drugs as a potential treatment option for COVID-19 (Akerström et al. 2009; Yang et al. 2020).

\section{Clinical relevance of $\mathrm{NO}$ and its applications}

\section{The role of NO in the treatment of respiratory and cardiovascular illnesses}

NO precursors, such as sodium nitroprusside (SNP), are commonly employed in treatment. SNP is generally given intravenously and releases NO as soon as it reaches circulation. It is commonly used as a vasodilator to treat acute hypertension. However, because intravenous administration of these medications can cause systemic vasodilation and arterial hypotension (Snijder et al. 2016), alternative treatments have kindled people's curiosity.

Healthy paranasal sinus epithelial cells express NOS and continually generate substantial quantities of NO gas (Mannick 1995). NO enters the deep areas of the lungs at low concentrations through inhaled air, encouraging bronchial dilatation, vasodilation and enhancing oxygen intake in the lungs (Ahmad et al. 2019; Letko et al. 2020). NO is scavenged by haemoglobin $(\mathrm{Hb})$ upon entering in circulation, limiting systemic vasodilation (Shang et al. 2020). The use of inhaled NO (iNO) as a selective pulmonary vasodilator in the treatment of respiratory failure in lung disorders has been investigated (Andersen et al. 2020). The FDA has authorised iNO for the treatment of respiratory infections and lung bacterial infections in new-borns (Hoffmann et al. 2020; Phan 2020). Inhaled NO treatment has been related to severe respiratory and inflammatory disorders and has been shown to be helpful in surgery and organ transplantation in animal trials. Despite the lack of evidence of iNO therapy adverse effects, it is important to monitor met-myoglobin, nitrogen dioxide $\left(\mathrm{NO}_{2}\right)$ levels and blood coagulation changes on a regular basis (He et al. 2020; Tahir Ul Qamar et al. 2020).

Coronavirus primarily infects people through their lungs, leading to respiratory failure and permanent lung damage in extreme cases. Based on the following therapeutic characteristics, researchers examined at the relevance of iNO as an adjuvant for coronavirus-induced respiratory failure.

\section{Role of NO in SARS and MERS}

SARS patients died at a rate of $10.5 \%$ globally, with around $20 \%$ having ARDS, which is characterised by severe lung infiltration and extensive consolidation (Stefano et al. 2020; Andreou et al. 2020; Tinker and Michenfelder 1976). Patients were routinely treated with corticosteroids and ribavirin to treat lung infection, but these medications had serious side effects, including femoral head osteonecrosis (Lundberg 2008). The best treatment for SARS was yet to be determined. Appropriate preventive actions were unquestionably required to halt the disease's progression.

Exogenous inhaled NO was reported to successfully restore arterial oxygenation in severe SARS patients while simultaneously suppressing the virus in a study done in May-July 2003. (Scadding 2007). Following iNO treatment, average $\mathrm{SpO}_{2}$ increased to $99 \%$, while oxygen supply was decreased to $2 \mathrm{~L} / \mathrm{min}$ in this research.

Furthermore, even after discontinuing NO inhalation, $\mathrm{SpO}_{2}$ remained high. The density of pulmonary infiltration reduced considerably, and decreased spread or density of lung infiltrates was observed. Two patients in the control group died, but the other six recovered and were discharged within 8 weeks of the study's conclusion. These findings revealed that iNO has good potential for treating SARS (Martel et al. 2020b).

Non-invasive ventilation (NIV) was widely employed for patients with associated acute hypoxemic respiratory failure (AHRF) during the MERS epidemic in 2012, while its overall efficacy remained debatable (Frostell et al. 1993). On August 9, 2018, researchers published findings from a multicentre study of severe MERS patients hospitalized between September 2012 and October 2015 at 14 collaborating tertiary care institutions in five Saudi cities. A total of 302 MERS cases were included in this study. Only 
invasive mechanical ventilation was utilized in $105(35 \%)$ of the patients, whereas invasive mechanical ventilation was employed in 197 (65\%) of the patients (MV). Patients treated with NIV were more likely than invasive MV patients to require iNO later, indicating the importance of iNO as adjuvant therapy in the treatment of MERS (Ichinose et al. 2004). Many clinical studies have been tried based on the encouraging results from previous SARS and MERS patients.

\section{Application of NO in the therapy of COVID-19}

In another study, around 26\% of COVID-19 patients required ICU care, with $61 \%$ developing ARDS (Barnes and Brisbois 2020; Pedersen et al. 2018). Invasive ventilation becomes essential after ARDS develops in individuals with hypoxemia (Yu et al. 2019). Furthermore, in severely sick patients, there is no alternative for oxygen-breathing assistance. Therefore, iNO has been investigated as a potential alternate rescue technique in COVID-19. In March 2020, Harvard University and Air Force Medical University started a multicentre clinical research to examine if continuous NO inhalation might be used as a rescue therapy to improve COVID-19 patients' oxygenation and survival. Patients may be gradually weaned off iNO once $\mathrm{PaO}_{2} / \mathrm{FiO}_{2}$ reached $>300 \mathrm{mmHg}$ within $24 \mathrm{~h}$, according to the findings. $\mathrm{NO}_{2}(2 \mathrm{ppm})$ and methemoglobin (5\%) levels were continuously monitored during the experiment to verify that it ran smoothly (Manocha et al. 2003). The outcomes have not been published yet.

In May 2020, University Health Network submitted a clinical research on the safety and effectiveness of highdose iNO (160 ppm, high medical dose) in COVID-19 patients on mechanical ventilation in reversing viral load and respiratory failure. The primary outcome was COVID19 PCR status from tracheal aspirate at the end of therapy (Chen et al. 2004). Similar studies were conducted, such as EUCTR2020-001,329-30-AT (Peiris et al. 2003), which focused on iNO treatment in failing pulmonary patients.

Tufts Medical Center conducted a pilot randomizedcontrolled (2:1) open-label study of iNO to avoid aggravation of severe illness in 42 COVID-19 dyspnoea patients in the same month. The participants were given NO through an iNO pulse device, and the primary goal was to see if iNO treatment reduces the progression of systemic hypoxia over 28 days (Lai 2005). Nitric Solutions-Mobile Unit (Arabi et al. 2014) is doing a similar experiment with NCT03331445, focusing on patients with respiratory distress.

On August 26, 2020, Massachusetts General Hospital announced the results of a clinical trial of iNO in pregnant patients with severe COVID-19. In the months of April through June 2020, they received a total of 39 treatments of high-dose NO (160-200 ppm) administered twice a day.
Following the start of $\mathrm{NO}$ administration, there was an improvement in cardiopulmonary function, as evidenced by an increase in systemic oxygenation among those with baseline hypoxemia in each administration session and a decrease in tachypnea in all patients in each administration session (Alraddadi et al. 2019). The researchers discovered that a dose of 160-200 ppm iNO was well tolerated by pregnant women with hypoxic respiratory failure (Yang et al. 2020).

With the COVID-19 pandemic affecting tens of millions of people throughout the world, it is more important than ever to discover safe and effective ways to stop the illness from spreading. NO has been found to help patients recover by inhibiting viral transmission, enhancing viral clearance and aiding in viral clearance. As a result, researchers postulated that exogenous NO may help prevent SARS-CoV-2 infection, and iNO has just been proven to be effective.

A randomised clinical trial of iNO was conducted to decrease COVID-19 infection among healthcare workers. It was aimed to help healthcare workers who came into contact with COVID-19 patients on a daily basis. The incidence of COVID-19 was evaluated between the iNO and control groups. Based on clinical evidence from China and Italy, iNO inhalation was projected to reduce the prevalence to 5\% (Wang 2020).

\section{COVID-19 and sex differences}

Stratified data by sex is seldom reported in the literature, and recent information on coronavirus disease 2019 (COVID19) and its results are much the same. Approximately 1.6 to 2.8 male fatalities per 1000 female deaths are reported by nations participating in the Global Health $50 / 50$ project (Bhopal 2020). Data from China, Korea and Europe show comparable case of fatality percentages, as well as a likely age interaction (Dudley and Lee 2020; Gebhard et al. 2020). Consistent findings from observational studies indicate that men and the elderly are highly represented among cases of severe disease (Guan et al. 2020; Wang et al. 2020a, b; Petrilli et al. 2020), intensive care unit admissions (Simonnet et al. 2020; Grasselli et al. 2020; Yang et al. 2020) and infection-related mortality. Studies stratified by sex have also shown that male sex is a risk factor for poor outcomes and higher mortality (Dudley and Lee 2020; Petrilli et al. 2020; Al-Rousan and Al-Najjar 2020; Alkhouli et al. 2020; Jin et al. 2020; Qin et al. 2020). Due to the nature of examining an emerging illness, large, rigorous sex-stratified studies are restricted.

In COVID-19-related morbidity and mortality, sex differences (chromosomes, reproductive organs and related sex factors) likely combine with gender-specific factors (appearances and activities defined by social and cultural/traditional roles) to explain the disparity (Gebhard et al. 2020). Men 
are more likely than women to smoke and drink alcohol (Reitsma et al. 2017; GBD 2015 Tobacco Collaborators 2017), and they have higher rates of pre-existing conditions that make it more likely that they will die from COVID19. In addition, even after adjusting for age, the impact of comorbidities on COVID-19 mortality was larger in men than in women, according to a sex-stratified analysis. The different responses to the severe acute respiratory syndrome coronavirus 2 (SARS-CoV-2) virus by sex might be due to a variety of molecular processes. However, the relationship between sex and COVID-19 health outcomes is rarely studied or translated into prevention or clinical settings, regardless of its magnitude or independence. Numerous factors, which are more prevalent in males, almost certainly contribute to worse COVID-19 outcomes, and concerns have been raised about the possibility of ACE inhibitors or angiotensin receptor blockers having detrimental effects in COVID-19. The immunological response is that females have a higher total immune response whereas men are more prone to produce the cytokine storm with poor COVID-19 results. Men have a lower survival rate than women, which may be explained by immunomodulation by sex hormones, age and $\mathrm{X}$-linked gene expression and provide an insight on course of infection and sex differences (Haitao et al. 2020). Clinical studies are currently being conducted to evaluate the effectiveness of such treatment in COVID-19 patients, as well as whether it varies by gender. The relationship between biological sex and the risk of infection and disease prognosis, on the other hand, is complicated, and the evidence provided is inconsistent.

While the total urine nitrate excretion does not vary between the two groups, the findings of an investigation demonstrate that the whole-body conversion of L-arginine to nitrate is more in healthy women than in males (Forte et al. 1998). The amount of nitrate excreted in the urine during a 36-h period is linked with the mean arterial pressure (MAP) throughout the whole group of patients investigated, and with serum 17-estradiol levels in the female group, respectively. Nitrate is formed by the oxidation of $\mathrm{NO}$, which is generated by the enzyme NO synthase from the amino acid L-arginine. After finding a strong correlation between gender and urine nitrate excretion, they investigated the possibility that nitric oxide synthesis is affected by gender difference also which could be a reason for increased infectivity in males than females.

\section{Limitations of NO in COVID-19 scenario}

Before invasive therapy, inhaled NO has been recommended as an alternate rescue technique, particularly for alleviating hypoxemia. Recent Italian investigations, on the other hand, demonstrate that $\mathrm{NO}$ is ineffective in restoring oxygenation in patients on long-term mechanical ventilation who have developed chronic hypoxemia ( $\mathrm{Li}$ et al. 2020). Damage from effectors and a high viral infection might explain why NO is ineffective in treating people who need a lot of oxygen. In the vascular and immunological systems, target effectors of NO are usually cells or viruses. As a result, for critically ill COVID-19 patients, routine breathing support and oxygenation treatment should focus on more strong antiviral medications. Therefore, iNO therapy should be evaluated in this context, especially in treating critically sick patients.

Despite significant research into the therapeutic benefits of iNO in COVID-19, the dose of iNO that is safe and beneficial is unknown. COVID-19 patients were given therapeutic doses ranging from 20 to $300 \mathrm{ppm}$. Quite a few researches have been conducted at iNO levels of 80, 150 and $160 \mathrm{ppm}$ for safety and effectiveness (Parikh et al. 2020). The results of these researches have yet to be made public. Only a few studies have shown that therapeutic devices for iNO, such as GENOSYL, LungFit Delivery System and INO pulse, are effective or safe in the treatment of COVID-19 (Tsui et al. 2003).

\section{Conclusion}

COVID-19 patients exhibited decreased NO levels and bioavailability, indicating that exogenous NO supplementation might aid in infection prevention or treatment. Here, the overall features and likely pathways of how NO functions in COVID-19 pathogenesis, as well as its possible therapeutic uses, are addressed. Inhaled NO may be used for COVID-19 prophylaxis and management at many phases, including viral entry prevention, providing symptomatic relief critically ill patients and adjuvant treatment for mechanically ventilated patients. Despite its potential, safety and efficacy of iNO must be investigated further.

\section{Future perspectives}

COVID-19 has emerged as a pandemic with the potential to overwhelm the body and healthcare system, and patients urgently need effective medications to halt the illness in their body and societies. While the hunt for a vaccine and specialized therapies continues, most medical research is focusing on the pathophysiology of the illness to see if there are any possible places of intervention. In other pulmonary disease models, nitric oxide has shown potential for reducing inflammation, and early proofs of concept for COVID-19 treatment are desperately needed. The potential of nitric oxide (NO) for the treatment of coronavirus and COVID-19 infection has received more attention in the last 2 months. When administered to the correct population and at the right stage of illness, 
exogenous NO treatment may be an appealing and viable option for patients. Nitric oxide therapy might be crucial in the world's battle against such an impending danger to public health if its effectiveness is shown as pharma companies seek its approval for COVID-19. NO-based prodrugs such as R-107 and COViNOX, two well-known examples, are now tested in clinical trials against the COVID-19 virus. So it is worth reviewing the literature in order to determine whether or if this simple chemical is useful in treating COVID-19, as well as the potential mechanism of action against coronaviruses and the implications of the findings for future studies in this area of inquiry. If the bioavailability of NO is discovered to be less than ideal, it may be beneficial to introduce the usage of NO boosters and clinically authorised NO-releasing substances with the goal of delivering NO to the body. As a result, the potent antiviral actions of $\mathrm{NO}$ against coronaviruses, as well as the role it plays in alleviating the clinical severity of COVID19 , justify the decision to include $\mathrm{NO}$ as a treatment option for this illness. In addition, using nanoparticles that release NO can target the pathophysiology of the virus in the respiratory tract and may stop it from spreading throughout the body. Successful outcomes would help to improve patient outcomes and reduce the burden on healthcare systems. Overall, NO has proved beneficial for millions of critically ill patients around the world since it was discovered and studied. Continuing on this path is a worthwhile endeavour.

Author contribution B. Mathew and Roshni P.R. planned the study and edited the manuscript. Rajalakshmi R, Anjana C and Roshini P.R. wrote the original draft preparation. Mazhuvancherry K. U, Lotfi A., Roshni P. R., B. Mathew, Abdullah G.A., M. Pannipara and Lotfi Aleya did the data curation and proof reading.

Funding Institute of research and consulting studies at King Khalid University funded this research through grant no 3-N-20/21 and the support of research centre for advanced material science.

Data availability The datasets used and analysed during the current study are available from the corresponding author on reasonable request.

\section{Declarations}

Ethics approval and consent to participate Not applicable.

Consent for publication Not applicable.

Competing interests The authors declare no competing interests.

\section{References}

Abou-Arab O, Huette P, Debouvries F et al (2020) Inhaled nitric oxide for critically ill Covid-19 patients: a prospective study. Crit Care 24:645. https://doi.org/10.1186/s13054-020-03371-x
Adusumilli NC, Zhang D, Friedman JM, Friedman AJ (2020) Harnessing nitric oxide for preventing, limiting and treating the severe pulmonary consequences of COVID-19. Nitric Oxide 103:4-8

Agalioti T, Lomvardas S, Parekh B et al (2000) Ordered recruitment of chromatin modifying and general transcription factors to the IFN- $\beta$ promoter. Cell 103:667-678. https://doi.org/10. 1016/s0092-8674(00)00169-0

Ahmad R, Hussain A, Ahsan H (2019) Peroxynitrite: cellular pathology and implications in autoimmunity. J Immunoassay Immunochem 40:123-138

Akaberi D, Krambrich J, Ling J et al (2020) Mitigation of the replication of SARS-CoV-2 by nitric oxide in vitro. Redox Biol 37:101734. https://doi.org/10.1016/j.redox.2020.101734

Akaike T, Fujii S, Kato A et al (2000) Viral mutation accelerated by nitric oxide production during infection in vivo. FASEB $\mathrm{J}$ 14:1447-1454. https://doi.org/10.1096/fj.14.10.1447

Akerström S, Mousavi-Jazi M, Klingström J et al (2005) Nitric oxide inhibits the replication cycle of severe acute respiratory syndrome coronavirus. J Virol 79:1966-1969

Akerström S, Gunalan V, Keng CT et al (2009) Dual effect of nitric oxide on SARS-CoV replication: viral RNA production and palmitoylation of the $S$ protein are affected. Virology 395:1-9

Akter F, Coghlan G, de Mel A (2016) Nitric oxide in paediatric respiratory disorders: novel interventions to address associated vascular phenomena? Ther Adv Cardiovasc Dis 10:256-270

Alamdari DH (2020) Application of methylene blue -vitamin C -N-acetyl cysteine for treatment of critically ill COVID-19 patients, report of a phase-I clinical trial. Eur J Pharmacol 885:173494

Alessandri F, Pugliese F, Ranieri VM (2018) The role of rescue therapies in the treatment of severe ARDS. Respir Care 63:92-101

Alkhouli M, Nanjundappa A, Annie F et al (2020) Sex differences in case fatality rate of COVID-19: Insights from a multinational registry. Mayo Clin Proc 95:1613-1620. https://doi.org/10. 1016/j.mayocp.2020.05.014

Alraddadi BM, Qushmaq I, Al-Hameed FM et al (2019) Noninvasive ventilation in critically ill patients with the Middle East respiratory syndrome. Influenza Other Respi Viruses 13:382-390

Al-Rousan N, Al-Najjar H (2020) Data analysis of coronavirus COVID19 epidemic in South Korea based on recovered and death cases. J Med Virol 92:1603-1608. https://doi.org/10.1002/jmv.25850

Al-Sehemi AG, Olotu FA, Dev S, Paninipara M, Soliman ME, Carradori S, Mathew B (2020) Natural products database screening for the discovery of naturally occurring SARS-CoV-2 spike glycoprotein blockers. ChemistrySelect 4:6614-6619

Alvarez RA, Berra L, Gladwin MT (2020) Home nitric oxide therapy for COVID-19. Am J Respir Crit Care Med 202:16-20

Alzahrani FA, Saadeldin IM, Ahmad A et al (2020) The potential use of mesenchymal stem cells and their derived exosomes as immunomodulatory agents for COVID-19 patients. Stem Cells Int 2020:8835986. https://doi.org/10.1155/2020/8835986

Amoretti M, Amsler C, Bonomi G et al (2002) Production and detection of cold antihydrogen atoms. Nature 419:456-459

Amraei R, Rahimi N (2020) COVID-19, renin-angiotensin system and endothelial dysfunction. Cells 9:1652

Andersen KG, Rambaut A, Lipkin WI et al (2020) The proximal origin of SARS-CoV-2. Nat Med 26:450-452

Andreou A, Trantza S, Filippou D et al (2020) COVID-19: the potential role of copper and $\mathrm{N}$-acetylcysteine (NAC) in a combination of candidate antiviral treatments against SARS-CoV-2. In Vivo 34:1567-1588

Arabi YM, Arifi AA, Balkhy HH et al (2014) Clinical course and outcomes of critically ill patients with Middle East respiratory syndrome coronavirus infection. Ann Intern Med 160:389-397 
Báez-Santos YM, St John SE, Mesecar AD (2015) The SARS-coronavirus papain-like protease: structure, function and inhibition by designed antiviral compounds. Antiviral Res 115:21-38

Bambouskova M, Gorvel L, Lampropoulou V et al (2018) Electrophilic properties of itaconate and derivatives regulate the IкB $\zeta-\mathrm{ATF} 3$ inflammatory axis. Nature 556:501-504. https://doi.org/10.1038/ s41586-018-0052-z

Banu N, Panikar SS, Leal LR, Leal AR (2020) Protective role of ACE2 and its downregulation in SARS-CoV-2 infection leading to macrophage activation syndrome: therapeutic implications. Life Sci 256:117905

Barnes M, Brisbois EJ (2020) Clinical use of inhaled nitric oxide: local and systemic applications. Free Radic Biol Med 152:422-431

Bartee E, McFadden G (2013) Cytokine synergy: an underappreciated contributor to innate anti-viral immunity. Cytokine 63:237-240. https://doi.org/10.1016/j.cyto.2013.04.036

Baxter FJ, Randall J, Miller JD et al (2002) Rescue therapy with inhaled nitric oxide in critically ill patients with severe hypoxemic respiratory failure (Brief report). Can J Anaesth 49:315-318

Becker RC (2020) COVID-19 update: Covid-19-associated coagulopathy. J Thromb Thrombolysis 50:54-67

Berlin I, Thomas D, Le Faou A-L, Cornuz J (2020) COVID-19 and smoking. Nicotine Tob Res 22:1650-1652

Bhopal R (2020) Covid-19 worldwide: we need precise data by age group and sex urgently. BMJ 369:m1366. https://doi.org/10.1136/ bmj.m1366

Bi Z, Reiss CS (1995) Inhibition of vesicular stomatitis virus infection by nitric oxide. J Virol 69:2208-2213. https://doi.org/10.1128/ JVI.69.4.2208-2213.1995

Blanco-Melo D, Nilsson-Payant BE, Liu W-C et al (2020) Imbalanced host response to SARS-CoV-2 drives development of COVID19. Cell 181:1036-1045.e9. https://doi.org/10.1016/j.cell.2020. 04.026

Bohlen HG (2015) Nitric oxide and the cardiovascular system. Compr Physiol 5:808-823. https://doi.org/10.1002/cphy.c140052

Boutin S, Hildebrand D, Boulant S et al (2021) Host factors facilitating SARS-CoV-2 virus infection and replication in the lungs. Cell Mol Life Sci 78:5953-5976

Buckley MS, Agarwal SK, Garcia-Orr R et al (2021) Comparison of fixed-dose inhaled epoprostenol and inhaled nitric oxide for acute respiratory distress syndrome in critically ill adults. J Intensive Care Med 36:466-476

Busè M, Graziano F, Lunetta F et al (2018) Inhaled nitric oxide as a rescue therapy in a preterm neonate with severe pulmonary hypertension: a case report. Ital J Pediatr 44. https://doi.org/10. 1186/s13052-018-0494-9

Cai H, Harrison DG (2000) Endothelial dysfunction in cardiovascular diseases: the role of oxidant stress. Circ Res 87:840-844. https:// doi.org/10.1161/01.res.87.10.840

Chang R, Mamun A, Dominic A, Le N-T (2020) SARS-CoV-2 mediated endothelial dysfunction: the potential role of chronic oxidative stress. Front Physiol 11:605908. https://doi.org/10.3389/ fphys.2020.605908

Channappanavar SP (2017) Pathogenic human coronavirus infections: causes and consequences of cytokine storm and immunopathology. Semin Immunopathol 39:529-539

Chen L, Liu P, Gao H et al (2004) Inhalation of nitric oxide in the treatment of severe acute respiratory syndrome: a rescue trial in Beijing. Clin Infect Dis 39:1531-1535

Chen C, Zhang XR, Ju ZY, He WF (2020) Advances in the research of mechanism and related immunotherapy on the cytokine storm induced by coronavirus disease 2019. Zhonghua Shao Shang Za Zhi 36:471-475. https://doi.org/10.3760/cma.j.cn501120-20200 224-00088
Chen N, Zhou M, Dong X et al (2020) Epidemiological and clinical characteristics of 99 cases of 2019 novel coronavirus pneumonia in Wuhan, China: a descriptive study. Lancet 395:507-513

Cheng S-C, Joosten LAB, Netea MG (2014) The interplay between central metabolism and innate immune responses. Cytokine Growth Factor Rev 25:707-713. https://doi.org/10.1016/j.cytog fr.2014.06.008

Clark IA (2007) The advent of the cytokine storm. Immunol Cell Biol 85:271-273. https://doi.org/10.1038/sj.icb.7100062

Colasanti M, Persichini T, Venturini G, Ascenzi P (1999) S-nitrosylation of viral proteins: molecular bases for antiviral effect of nitric oxide. IUBMB Life 48:25-31. https://doi.org/10.1080/ 713803459

Connors JM, Levy JH (2020) COVID-19 and its implications for thrombosis and anticoagulation. Blood 135:2033-2040

Creagh T, Ruckle JL, Tolbert DT et al (2001) Safety and pharmacokinetics of single doses of (+)-calanolide a, a novel, naturally occurring nonnucleoside reverse transcriptase inhibitor, in healthy, human immunodeficiency virus-negative human subjects. Antimicrob Agents Chemother 45:1379-1386. https://doi. org/10.1128/AAC.45.5.1379-1386.2001

Croen KD (1993) Evidence for antiviral effect of nitric oxide. Inhibition of herpes simplex virus type 1 replication. J Clin Invest 91:2446-2452

Currens MJ, Gulakowski RJ, Mariner JM et al (1996) Antiviral activity and mechanism of action of calanolide A against the human immunodeficiency virus type-1. J Pharmacol Exp Ther 279:645-651

Drucker DJ (2020) Coronavirus infections and type 2 diabetes-shared pathways with therapeutic implications. Endocr Rev 41:457-470

Dudley JP, Lee NT (2020) Disparities in age-specific morbidity and mortality from SARS-CoV-2 in China and the Republic of Korea. Clin Infect Dis 71:863-865. https://doi.org/10.1093/cid/ciaa354

England JT, Abdulla A, Biggs CM et al (2021) Weathering the COVID19 storm: lessons from hematologic cytokine syndromes. Blood Rev 45:100707. https://doi.org/10.1016/j.blre.2020.100707

Everett W, Scurr DJ, Rammou A et al (2016) A Material Conferring Hemocompatibility Sci Rep 6:26848

Fehr AR, Perlman S (2015) Coronaviruses: an overview of their replication and pathogenesis. Methods Mol Biol 1282:1-23

Ferrari M, Santini A, Protti A et al (2020) Inhaled nitric oxide in mechanically ventilated patients with COVID-19. J Crit Care 60:159-160

Forte P, Kneale BJ, Milne E et al (1998) Evidence for a difference in nitric oxide biosynthesis between healthy women and men. Hypertension 32:730-734. https://doi.org/10.1161/01.hyp.32.4. 730

Fraser DD (2020) Endothelial injury and glycocalyx degradation in critically ill coronavirus disease 2019 patients: implications for microvascular platelet aggregation. Crit Care Explor 2:0194

Friebe A, Sandner P, A, (2020) Schmidtko, cGMP: a unique 2nd messenger molecule - recent developments in cGMP research and development. Naunyn Schmiedeberg's Arch Pharmacol 393:287-302

Frostell CG, Blomqvist H, Hedenstierna G et al (1993) Inhaled nitric oxide selectively reverses human hypoxic pulmonary vasoconstriction without causing systemic vasodilation. Anesthesiology 78:427-435

Garfield B, McFadyen C, Briar C et al (2021) Potential for personalised application of inhaled nitric oxide in COVID-19 pneumonia. Br J Anaesth 126:e72-e75

GBD (2015) Tobacco Collaborators (2017) Smoking prevalence and attributable disease burden in 195 countries and territories, 1990-2015: a systematic analysis from the Global Burden of 
Disease Study 2015. Lancet 389:1885-1906. https://doi.org/10. 1016/S0140-6736(17)30819-X

Gebhard C, Regitz-Zagrosek V, Neuhauser HK et al (2020) Impact of sex and gender on COVID-19 outcomes in Europe. Biol Sex Differ 11:29. https://doi.org/10.1186/s13293-020-00304-9

Gebistorf F, Karam O, Wetterslev J, Afshari A (2016) Inhaled nitric oxide for acute respiratory distress syndrome (ARDS) in children and adults. Cochrane Database Syst Rev CD002787. https://doi.org/10.1002/14651858.CD002787.pub3

Gibaldi M (1993) What is nitric oxide and why are so many people studying it? J Clin Pharmacol 33:488-496

Gimbrone MA Jr, García-Cardeña G (2016) Endothelial cell dysfunction and the pathobiology of atherosclerosis. Circ Res 118:620-636. https://doi.org/10.1161/CIRCRESAHA.115. 306301

Goeijenbier M (2012) Review: viral infections and mechanisms of thrombosis and bleeding. J Med Virol 84:1680-1696

Gopal K, Varma PK (2020) Cardiac surgery during the times of COVID-19. Indian J Thorac Cardiovasc Surg 36:1-2

Grasselli G, Zangrillo A, Zanella A et al (2020) Baseline characteristics and outcomes of 1591 patients infected with SARSCoV-2 admitted to ICUs of the Lombardy region, Italy. JAMA 323:1574-1581. https://doi.org/10.1001/jama.2020.5394

Guan W-J, Ni Z-Y, Hu Y et al (2020) Clinical characteristics of coronavirus disease 2019 in China. N Engl J Med 382:1708-1720. https://doi.org/10.1056/NEJMoa2002032

Guo X-ZJ, Thomas PG (2017) New fronts emerge in the influenza cytokine storm. Semin Immunopathol 39:541-550

Guzik TJ, Korbut R, Adamek-Guzik T (2003) Nitric oxide and superoxide in inflammation and immune regulation. J Physiol Pharmacol 54:469-487

Haagmans BL, Osterhaus ADME (2006) Coronaviruses and their therapy. Antiviral Res 71:397-403

Haddad E, Lowson SM, Johns RA et al (2000) Use of inhaled nitric oxide perioperatively and in intensive care patients. Anesthesiology 92:1821-1825

Haitao T, Vermunt JV, Abeykoon J et al (2020) COVID-19 and sex differences: mechanisms and biomarkers. Mayo Clin Proc 95:2189-2203. https://doi.org/10.1016/j.mayocp.2020.07.024

Hati S, Bhattacharyya S (2020) Impact of thiol-disulfide balance on the binding of covid-19 spike protein with angiotensinconverting enzyme 2 receptor. ACS Omega 5:16292-16298. https://doi.org/10.1021/acsomega.0c02125

He J, Hu L, Huang X et al (2020) Potential of coronavirus 3C-like protease inhibitors for the development of new anti-SARSCoV-2 drugs: insights from structures of protease and inhibitors. Int J Antimicrob Agents 56:106055

Hedenstierna G, Chen L, Hedenstierna M et al (2020) Nitric oxide dosed in short bursts at high concentrations may protect against Covid 19. Nitric Oxide 103:1-3

Hermann E, Idziorek T, Kusnierz JP et al (1997) Role of nitric oxide in the regulation of lymphocyte apoptosis and HIV-1 replication. Int J Immunopharmacol 19:387-397

Hoffmann M, Kleine-Weber H, Schroeder S et al (2020) SARSCoV-2 cell entry depends on ACE2 and TMPRSS 2 and is blocked by a clinically proven protease inhibitor. Cell 181:271280.e8

Hottz ED, Azevedo-Quintanilha IG, Palhinha L et al (2020) Platelet activation and platelet-monocyte aggregate formation trigger tissue factor expression in patients with severe COVID-19. Blood 136:1330-1341

Huang C, Wang Y, Li X et al (2020) Clinical features of patients infected with 2019 novel coronavirus in Wuhan, China. Lancet 395:497-506
Hunter CA, Jones SA (2015) IL-6 as a keystone cytokine in health and disease. Nat Immunol 16:448-457. https://doi.org/10. 1038/ni.3153

Ichinose F, Roberts JD Jr, Zapol WM (2004) Inhaled nitric oxide: a selective pulmonary vasodilator: current uses and therapeutic potential. Circulation 109:3106-3111

Jin J-M, Bai P, He W et al (2020) Gender differences in patients with COVID-19: focus on severity and mortality. Front Public Health 8:152. https://doi.org/10.3389/fpubh.2020.00152

Jung K, Gurnani A, Renukaradhya GJ, Saif LJ (2010) Nitric oxide is elicited and inhibits viral replication in pigs infected with porcine respiratory coronavirus but not porcine reproductive and respiratory syndrome virus. Vet Immunol Immunopathol 136:335-339

Karimova RG (2021) Comparative activity of the nitric oxide (II) system the process of developing of an immune response in guinea pigs after injection of anti-brucellosis vaccines. Biosci Biotechnol Res Commun 14:15-19

Karupiah G, Harris N (1995) Inhibition of viral replication by nitric oxide and its reversal by ferrous sulfate and tricarboxylic acid cycle metabolites. J Exp Med 181:2171-2179

Keyaerts E, Vijgen L, Chen L et al (2004) Inhibition of SARS-coronavirus infection in vitro by $\mathrm{S}$-nitroso-N-acetylpenicillamine, a nitric oxide donor compound. Int J Infect Dis 8:223-226

Kleinbongard P (2003) Plasma nitrite reflects constitutive nitric oxide synthase activity in mammals, Free Radic. Biol Med 35:790-796

Klinger JR (2002) Inhaled nitric oxide in ARDS. Crit Care Clin 18(45-68):vi

Klingström J, Akerström S, Hardestam J et al (2006) Nitric oxide and peroxynitrite have different antiviral effects against hantavirus replication and free mature virions. Eur J Immunol 36:26492657. https://doi.org/10.1002/eji.200535587

Korhonen R, Lahti A, Kankaanranta H, Moilanen E (2005) Nitric oxide production and signaling in inflammation. Curr Drug Targets Inflamm Allergy 4:471-479

Kumar R, Harilal S, Al-Sehemi AG et al (2021a) The chronicle of COVID-19 and possible strategies to curb the pandemic. Curr Med Chem 28:2852-2886

Kumar R, HarilalS A-S, Paninipara M, Behl T, Mathew GE, Mathew B (2021) COVID-19 and domestic animals: exploring the species barrier crossing, zoonotic and reverse zoonotic transmission of SARS-CoV-2. Curr Pharm Des 22:1194-1201

Kumar R, Harilal S, Sabitha M, Pappachan LK, Roshni PR, Mathew B (2021b). Current perspective of COVID-19 on neurology: a mechanistic insight. Comb Chem High Throughput Screen. https://pubmed.ncbi.nlm.nih.gov/34353250/

Kuprash DV, Nedospasov SA (2016) Molecular and cellular mechanisms of inflammation. Biochemistry (mosc) 81:1237-1239

Kvietys PR, Granger DN (2012) Role of reactive oxygen and nitrogen species in the vascular responses to inflammation. Free Radic Biol Med 52:556-592

Lai ST (2005) Treatment of severe acute respiratory syndrome. Eur J Clin Microbiol Infect Dis 24:583-591

Lee A, Butt W (2020) Nitric oxide: a new role in intensive care. Crit Care Resusc 22:72-79

Letko M, Marzi A, Munster V (2020) Functional assessment of cell entry and receptor usage for SARS-CoV-2 and other lineage B betacoronaviruses. Nat Microbiol 5:562-569

Li X, Fang P, Mai J et al (2013) Targeting mitochondrial reactive oxygen species as novel therapy for inflammatory diseases and cancers. J Hematol Oncol 6:19. https://doi.org/10.1186/ 1756-8722-6-19

Li H, Liu Z, Ge J (2020) Scientific research progress of COVID19/SARS-CoV-2 in the first five months. J Cell Mol Med 24:6558-6570 
Liu K, Fang Y-Y, Deng Y et al (2020) Clinical characteristics of novel coronavirus cases in tertiary hospitals in Hubei Province. Chin Med J (engl) 133:1025-1031. https://doi.org/10.1097/cm9.00000 00000000744

Long H, Nie L, Xiang X et al (2020) D-dimer and prothrombin time are the significant indicators of severe COVID-19 and poor prognosis. Biomed Res Int 2020:6159720

Lowenstein CJ, Hill SL, Lafond-Walker A et al (1996) Nitric oxide inhibits viral replication in murine myocarditis. J Clin Invest 97:1837-1843

Lu R, Zhao X, Li J et al (2020) Genomic characterisation and epidemiology of 2019 novel coronavirus: implications for virus origins and receptor binding. Lancet 395:565-574

Lundberg JO (2008) Nitric oxide and the paranasal sinuses. Anat Rec (hoboken) 291:1479-1484

Maadamanchi NR, Vendrov A, Runge MS (2005) Oxidative stress and cardiac disease. The American Journal of Med 25:29-38

Mahjoub Y, Rodenstein DO, Jounieaux V (2020) Severe Covid-19 disease: rather AVDS than ARDS? Crit Care 24:327

Mannick JB (1995) The antiviral role of nitric oxide. Res Immunol 146:693-697

Mannick JB (2006) Immunoregulatory and antimicrobial effects of nitrogen oxides. Proc Am Thorac Soc 3:161-165

Manocha S, Walley KR, Russell JA (2003) Severe acute respiratory distress syndrome (SARS): a critical care perspective. Crit Care Med 31:2684-2692

Martel J, Ko YF, Young JD, Ojcius DM (2020) Covid-19 accelerates endothelial dysfunction and nitric oxide deficiency. Microb Infect 22:168-171

Martel J, Ko Y-F, Young JD, Ojcius DM (2020) Could nasal nitric oxide help to mitigate the severity of COVID-19? Microbes Infect 22:168-171

Mĕlková Z, Esteban M (1995) Inhibition of vaccinia virus DNA replication by inducible expression of nitric oxide synthase. J Immunol 155:5711-5718

Michel JB (1998) Role of endothelial nitric oxide in the regulation of the vasomotor system. Pathol Biol 46:181-189

Miesbach W, Makris M (2020) COVID-19: coagulopathy, risk of thrombosis, and the rationale for anticoagulation. Clin Appl Thromb Hemost 26:1076029620938149

Moilanen E, Vapaatalo H (1995) Nitric oxide in inflammation and immune response. Ann Med 27:359-367

Monsalve-Naharro JÁ, Domingo-Chiva E, García Castillo S et al (2017) Inhaled nitric oxide in adult patients with acute respiratory distress syndrome. Farm Hosp 41:292-312

Nagy E, Eaton JW, Jeney V et al (2010) Red cells, hemoglobin, heme, iron, and atherogenesis. Arterioscler Thromb Vasc Biol 30:13471353. https://doi.org/10.1161/ATVBAHA.110.206433

Nambiar V, Sudevan R, Ajai A, Chattu VK (2018) Growing burden of stroke, recent advancements in management and global commitments: the way forward. J Pharm Pract Community Med 4:191-192

Ng KHL, Wu AKL, Cheng VCC et al (2005) Pulmonary artery thrombosis in a patient with severe acute respiratory syndrome. Postgrad Med J 81:e3. https://doi.org/10.1136/pgmj.2004.030049

Nguyen Dinh Cat A, Montezano AC, Burger D, Touyz RM (2013) Angiotensin II, NADPH oxidase, and redox signaling in the vasculature. Antioxid Redox Signal 19:1110-1120. https://doi.org/ 10.1089/ars.2012.4641

Nile SH, Nile A, Qiu J et al (2020) COVID-19: pathogenesis, cytokine storm and therapeutic potential of interferons. Cytokine Growth Factor Rev 53:66-70. https://doi.org/10.1016/j.cytogfr.2020.05.002

Nordberg J, Arnér ESJ (2001) Reactive oxygen species, antioxidants, and the mammalian thioredoxin system 1 This review is based on the licentiate thesis "Thioredoxin reductase-interactions with the redox active compounds 1-chloro-2,4-dinitrobenzene and lipoic acid" by Jonas Nordberg, 2001, Karolinska Institute, Stockholm, ISBN 91-631-1064-4. Free Radic Biol Med 31:1287-1312. https://doi.org/10.1016/s0891-5849(01)00724-9

O'Neill LAJ (2015) How low cholesterol is good for anti-viral immunity. Cell 163:1572-1574. https://doi.org/10.1016/j.cell.2015. 12.004

Ozdemir B, Yazici A (2020) Could the decrease in the endothelial nitric oxide (NO) production and NO bioavailability be the crucial cause of COVID-19 related deaths? Med. Hypotheses 144:109970

Parikh R, Wilson C, Weinberg J et al (2020) Inhaled nitric oxide treatment in spontaneously breathing COVID-19 patients. Ther Adv Respir Dis 14:1753466620933510

Pathan N, Hemingway CA, Alizadeh AA et al (2004) Role of interleukin 6 in myocardial dysfunction of meningococcal septic shock. Lancet 363:203-209. https://doi.org/10.1016/S0140-6736(03) 15326-3

Pedersen J, Hedegaard ER, Simonsen U et al (2018) Current and future treatments for persistent pulmonary hypertension in the newborn. Basic Clin Pharmacol Toxicol 123:392-406

Peiris JSM, Chu CM, Cheng VCC et al (2003) Clinical progression and viral load in a community outbreak of coronavirus-associated SARS pneumonia: a prospective study. Lancet 361:1767-1772

Pennathur S, Heinecke JW (2007) Oxidative stress and endothelial dysfunction in vascular disease. Curr Diab Rep 7:257-264. https:// doi.org/10.1007/s11892-007-0041-3

Petersen E, Koopmans M, Go U et al (2020) Comparing SARS-CoV-2 with SARS-CoV and influenza pandemics. Lancet Infect Dis 20:e238-e244. https://doi.org/10.1016/S1473-3099(20)30484-9

Petrilli CM, Jones SA, Yang J et al (2020) Factors associated with hospital admission and critical illness among 5279 people with coronavirus disease 2019 in New York City: prospective cohort study. BMJ 369:m1966. https://doi.org/10.1136/bmj.m1966

Phan T (2020) Genetic diversity and evolution of SARS-CoV-2. Infect Genet Evol 81:10426

Prakash A, Kaur S, Kaur C et al (2021) Efficacy and safety of inhaled nitric oxide in the treatment of severe/critical COVID-19 patients: a systematic review. Indian J Pharmacol 53:236-243

Qin L, Li X, Shi J et al (2020) Gendered effects on inflammation reaction and outcome of COVID-19 patients in Wuhan. J Med Virol 92:2684-2692. https://doi.org/10.1002/jmv.26137

Quan S, Yang L, Abraham NG, Kappas A (2001) Regulation of human heme oxygenase in endothelial cells by using sense and antisense retroviral constructs. Proc Natl Acad Sci U S A 98:12203-12208. https://doi.org/10.1073/pnas.211399398

Ramachandran RA, Lupfer C, Zaki H (2018) The inflammasome: regulation of nitric oxide and antimicrobial host defence. Adv Microb Physiol 72:65-115

Reghunathan R, Jayapal M, Hsu L-Y et al (2005) Expression profile of immune response genes in patients with severe acute respiratory syndrome. BMC Immunol 6:2. https://doi.org/10.1186/ 1471-2172-6-2

Reitsma MB, Fullman N, Ng M et al (2017) Smoking prevalence and attributable disease burden in 195 countries and territories, 1990-2015: a systematic analysis from the Global Burden of Disease Study 2015. Lancet 389:1885-1906. https://doi.org/10. 1016/s0140-6736(17)30819-x

Ricciardolo FLM (2003) Multiple roles of nitric oxide in the airways. Thorax 58:175-182

Ricciardolo FLM, Bertolini F, Carriero V, Högman M (2020) Nitric oxide's physiologic effects and potential as a therapeutic agent against COVID-19. J Breath Res 15:014001

Richardson S, Hirsch JS, Narasimhan M et al (2020) Presenting characteristics, comorbidities, and outcomes among 5700 patients hospitalized with COVID-19 in the New York City area. JAMA 323:2052-2059. https://doi.org/10.1001/jama.2020.6775 
Rimmelzwaan GF, Baars M, Fouchier RAM, Osterhaus ADME (2001) Inhibition of influenza virus replication by nitric oxide. Int Congr Ser 1219:551-555

Robbins RA, Grisham MB (1997) Nitric oxide. Int J Biochem Cell Biol 29:857-860

Rossaint R, Lewandowski K, Zapol WM (2014) Our paper 20 years later: inhaled nitric oxide for the acute respiratory distress syndrome-discovery, current understanding, and focussed targets of future applications. Intensive Care Med 40:1649-1658

Safaee Fakhr B, Wiegand SB, Pinciroli R et al (2020) High concentrations of nitric oxide inhalation therapy in pregnant patients with severe coronavirus disease 2019 (COVID-19). Obstet Gynecol 136:1109-1113

Sahni R, Ameer X, Ohira-Kist K, Wung J-T (2017) Non-invasive inhaled nitric oxide in the treatment of hypoxemic respiratory failure in term and preterm infants. J Perinatol 37:54-60

Sanchez EL, Lagunoff M (2015) Viral activation of cellular metabolism. Virology 479-480:609-618. https://doi.org/10.1016/j.virol. 2015.02.038

Saura M, Zaragoza C, McMillan A et al (1999) An antiviral mechanism of nitric oxide: inhibition of a viral protease. Immunity 10:21-28

Scadding G (2007) Nitric oxide in the airways. Curr Opin Otolaryngol Head Neck Surg 15:258-263

Shang J, Ye G, Shi K et al (2020) Structural basis of receptor recognition by SARS-CoV-2. Nature 581:221-224

Shenoy S (2020) Coronavirus (covid-19) sepsis: revisiting mitochondrial dysfunction in pathogenesis, aging, inflammation, and mortality. Inflamm Res 69:1077-1085

Shimabukuro-Vornhagen A, Gödel P, Subklewe M et al (2018) Cytokine release syndrome. J Immunother Cancer 6. https://doi. org/10.1186/s40425-018-0343-9

Siddiqui AJ, Jahan S, Ashraf SA et al (2021) Current status and strategic possibilities on potential use of combinational drug therapy against COVID-19 caused by SARS-CoV-2. J Biomol Struct Dyn 39:6828-6841. https://doi.org/10.1080/07391102.2020.1802345

Simonnet A, Chetboun M, Poissy J et al (2020) High prevalence of obesity in severe acute respiratory syndrome Coronavirus-2 (SARSCoV-2) requiring invasive mechanical ventilation. Obesity (silver Spring) 28:1195-1199. https://doi.org/10.1002/oby.22831

Snijder EJ, Decroly E, Ziebuhr J (2016) The nonstructural proteins directing coronavirus RNA synthesis and processing. Adv Virus Res 96:59-126

Song P, Li W, Xie J et al (2020) Cytokine storm induced by SARSCoV-2. Clin Chim Acta 509:280-287

Star RA (1993) Nitric oxide. Am J Med Sci 306:348-358

Stefano GB, Esch T, Kream RM (2020) Potential immunoregulatory and antiviral/SARS-CoV-2 activities of nitric oxide. Med Sci Monit 26:e925679

Surti M, Patel M, Adnan M et al (2020) Ilimaquinone (marine sponge metabolite) as a novel inhibitor of SARS-CoV-2 key target proteins in comparison with suggested COVID-19 drugs: designing, docking and molecular dynamics simulation study. RSC Adv 10:37707-37720. https://doi.org/10.1039/d0ra06379g

Susswein AJ, Katzoff A, Miller N, Hurwitz I (2004) Nitric oxide and memory. Neuroscientist 10:153-162

Tahir U1 Qamar M, Alqahtani SM, Alamri MA, Chen L-L (2020) Structural basis of SARS-CoV-2 3CLpro and anti-COVID-19 drug discovery from medicinal plants. J Pharm Anal 10:313-319

Takahashi N, Abe R, Hattori N et al (2020) Clinical course of a critically ill patient with severe acute respiratory syndrome coronavirus 2 (SARS-CoV-2). J Artif Organs 23:397-400

Tanaka T, Narazaki M, Kishimoto T (2016) Immunotherapeutic implications of IL-6 blockade for cytokine storm. Immunotherapy 8:959-970. https://doi.org/10.2217/imt-2016-0020
Tavazzi G, Pozzi M, Mongodi S et al (2020) Inhaled nitric oxide in patients admitted to intensive care unit with COVID-19 pneumonia. Crit Care 24:508

Tavazzi G, Pozzi M, Mongodi S et al (2020) Correction to: Inhaled nitric oxide in patients admitted to intensive care unit with COVID-19 pneumonia. Crit Care 24:665

Teijaro JR, Walsh KB, Rice S et al (2014) Mapping the innate signaling cascade essential for cytokine storm during influenza virus infection. Proc Natl Acad Sci U S A 111:3799-3804. https://doi. org/10.1073/pnas.1400593111

Teixeira R, Santos M, Gil V (2020) COVID-19 and cardiovascular comorbidities: an update. Rev Port Cardiol (engl Ed) 39:417-419

Teuwen L-A, Geldhof V, Pasut A, Carmeliet P (2020) COVID-19: the vasculature unleashed. Nat Rev Immunol 20:389-391. https:// doi.org/10.1038/s41577-020-0343-0

Thachil J (2020) What do monitoring platelet counts in COVID-19 teach us? J Thromb Haemost 18:2071-2072

Tinker JH, Michenfelder JD (1976) Sodium nitroprusside: pharmacology, toxicology and therapeutics. Anesthesiology 45:340-352

Toolsie O, Gomceli U, Diaz-Fuentes G (2019) Inhaled nitric oxide as an adjunct to thrombolytic therapy in a patient with submassive pulmonary embolism and severe hypoxemia. Case Rep Crit Care 2019:5184702

Tripathi P (2007) Nitric oxide and immune response. Indian J Biochem Biophys 44:310-319

Tsui PT, Kwok ML, Yuen H, Lai ST (2003) Severe acute respiratory syndrome: clinical outcome and prognostic correlates. Emerg Infect Dis 9:1064-1069

Turner MD, Nedjai B, Hurst T, Pennington DJ (2014) Cytokines and chemokines: at the crossroads of cell signalling and inflammatory disease. Biochim Biophys Acta 1843:2563-2582. https:// doi.org/10.1016/j.bbamcr.2014.05.014

Ubillas R, Jolad SD, Bruening RC et al (1994) SP-303, an antiviral oligomeric proanthocyanidin from the latex of Croton lechleri (Sangre de Drago). Phytomedicine 1:77-106. https://doi.org/10. 1016/s0944-7113(11)80026-7

Uehara EU, Shida B de S, de Brito CA (2015) Role of nitric oxide in immune responses against viruses: beyond microbicidal activity. Inflamm Res 64:845-852. https://doi.org/10.1007/ s00011-015-0857-2

Vabret N, Britton GJ, Gruber C et al (2020) Immunology of COVID19: current state of the science. Immunity 52:910-941. https:// doi.org/10.1016/j.immuni.2020.05.002

Varga Z (2020) Endothelial cell infection and endotheliitis in COVID19. Lancet 395:1417-1418

Wang Q (2020) Structural and functional basis of SARS-CoV-2 entry by using human ACE2. Cell 181:894-904

Wang D, Hu B, Hu C et al (2020a) Clinical characteristics of 138 hospitalized patients with 2019 novel coronavirus-infected pneumonia in Wuhan, China. JAMA 323:1061-1069

Wang X, Fang J, Zhu Y et al (2020b) Clinical characteristics of noncritically ill patients with novel coronavirus infection (COVID19) in a Fangcang Hospital. Clin Microbiol Infect 26:1063-1068. https://doi.org/10.1016/j.cmi.2020.03.032

Wang W, Liu X, Wu S et al (2020c) Definition and risks of cytokine release syndrome in 11 critically ill COVID-19 patients with pneumonia: analysis of disease characteristics. J Infect Dis 222:1444-1451. https://doi.org/10.1093/infdis/jiaa387

Wei Z-Y, Wang X-B, Ning X-D et al (2009) Nitric oxide inhibits the replication cycle of porcine parvovirus in vitro. Arch Virol 154:999-1003

World Health Organization (2022) COVID-19 dashboard. https://covid 19.who.int/. Accessed 23 Feb 2022

Wu Z, McGoogan JM (2020) Characteristics of and important lessons from the coronavirus disease 2019 (COVID-19) outbreak 
in China: Summary of a report of 72314 cases from the Chinese center for disease control and prevention. JAMA 323:1239-1242

Wu D, Sanin DE, Everts B et al (2016) Type 1 interferons induce changes in core metabolism that are critical for immune function. Immunity 44:1325-1336. https://doi.org/10.1016/j.immuni. 2016.06.006

Wyde PR, Ambrose MW, Meyerson LR, Gilbert BE (1993) The antiviral activity of SP-303, a natural polyphenolic polymer, against respiratory syncytial and parainfluenza type 3 viruses in cotton rats. Antiviral Res 20:145-154. https://doi.org/10.1016/01663542(93)90004-3

Xu W, Zheng S, Dweik RA, Erzurum SC (2006) Role of epithelial nitric oxide in airway viral infection. Free Radic Biol Med 41:19-28

Yang X, Yu Y, Xu J et al (2020) Clinical course and outcomes of critically ill patients with SARS-CoV-2 pneumonia in Wuhan, China: a single-centered, retrospective, observational study. Lancet Respir Med 8:475-481
Yu B, Ichinose F, Bloch DB, Zapol WM (2019) Inhaled nitric oxide: inhalation of NO. Br J Pharmacol 176:246-255

Zamanian RT, Pollack CV Jr, Gentile MA et al (2020) Outpatient inhaled nitric oxide in a patient with vasoreactive idiopathic pulmonary arterial hypertension and COVID-19 infection. Am J Respir Crit Care Med 202:130-132

Zheng KI, Gao F, Wang X-B et al (2020) Letter to the Editor: Obesity as a risk factor for greater severity of COVID-19 in patients with metabolic associated fatty liver disease. Metabolism 108:154244

Zimmermann P, Curtis N (2020) Coronavirus infections in children including COVID-19: an overview of the epidemiology, clinical features, diagnosis, treatment and prevention options in children. Pediatr Infect Dis J 39:355-368

Publisher's note Springer Nature remains neutral with regard to jurisdictional claims in published maps and institutional affiliations. 